\title{
Innovation Management in Times of Economic Crisis
}

UDK: $005.584 .2 ; 005.332: 338.124 .2$

DOI: 10.7595/management.fon.2013.0001

\begin{abstract}
Economic downturns are the least desirable but still inevitable conditions, which bring along many negative consequences on the living standard of citizens and business survival, development, further growth, and profitability. In such circumstances of economic crises, managers turn to the so-called quick reactive strategies aimed at retaining previous profit levels, in an attempt to protect their business from the downfall - thus securing its survival. However, it is determined that in a time of economic crisis, innovation management in most cases suffers the most. It becomes a neglected field of management, left for better economic conditions. Nevertheless, the question is whether managers in periods of economic downturns should neglect investing in innovations and how they should approach the innovation management field. In this paper, strategic implications of innovation management in the time of economic crisis are presented. In the first part of the paper the usual managers' behavior related to conducting business in times of economic crisis is described. In the second part of the paper proposals are given with regard to whether and how managers should implement innovation management strategies, in order to set up a strong base and precondition for future business growth, after the crisis is over, but also during the crisis itself.
\end{abstract}

Keywords: economic crisis, economic downturn, innovation management

\section{Introduction}

Since the last quarter of 2008, countries all around the world have been facing a deep economic crisis and the changes therewith connected, and it has been estimated that crisis repercussions will be in effect until 2014 , or even longer in certain industries. The industries in general have been weakened and shaken, unemployment has risen, and investments crucial for innovations and future growth are under risk. In many countries, governments have endorsed expenditure of billions of dollars for the purpose of founding stimulating funds, but the hard work of rebuilding of the damaged economies has just begun. The primary task of managers is to enforce various business decisions, mainly cost-inspired, in order to keep their organizations afloat, but they seem unaware of the fact that the key to return to long-term growth under these conditions is precisely the human capacity to innovate. By rational investments, national governments can slow down the economic downfall, speed up economic recovery and place a foundation for a strong and sustainable growth. However, most managers seem not to understand the possibility to use that basis in an efficient way, but only through innovation. This paper describes the process of innovation management in times of economic downturn, with the accent on its strategic implications to companies' business. We present the usual managerial behavior in a time of economic crisis, but also give recommendations for fruitful business behavior during such times.

\section{The usual managerial behaviour during the time of crisis}

The basic strategy to which managers of all companies resort during the time of crisis is the strategy of cost reduction (Hart, 2009). Dumbfounded by the unexpected downturn, reduced income of cash flow and revenue, pressed by deadlines and the need to react quickly, they find themselves involved in the inevitable necessity to provide for company's survival by reducing costs. The most frequently used strategies for cost reduction during the time of crisis in 2008/2010 were (Milić, 2011): 
- reduction of unlimited costs, such as training and education, fixed costs, IT costs, etc.

- freezing and/or reduction of compensation, i.e. income, bonuses, insurance, etc.

- labor redundancy

- delay and/or cancellation of capital investments and/or other investments.

- reduction of marketing costs, product sales and development, such as research and upgrading, economic propaganda, business trips, promotional materials and events, etc.

These strategies originate from the so-called reactive approach to crisis, when company management places as their top priority the immediate need to cut down business costs in order to enable the company's survival. In this case we have the classic upside-down cost reduction approach in which top management determines the amount of money by which costs should be reduced, assesses the main cost categories and gives directives to lower-level management to effect certain reductions, in order to achieve the amount of savings which was determined as necessary

However, the question is, in what measure so developed cost reduction strategies implemented on the spot during a crisis can bring benefits to organizations that use them. Usually, cost reduction strategies applied in such situation bring only short-term positive effects. When considering long-term situations, however, these organizations are forced to face serious damage to various aspects of their systems. This is caused by a shortage of needed resources, above all human resources, talented experts, but also repercussions of decreased productivity of the actual employees, their deficient education and knowledge innovation, lost enthusiasm, as well as the negative effects of falling behind the technological development, undeveloped or weakened market position and reduced revenue profitability. Altogether, this increases costs necessary to make up for the lost time later on (Milić, 2011).

The longer the crisis, the greater the above described negative long-term consequences of applying the aforementioned strategies.

\section{The usual and current states of innovation in times of economic crisis}

Due to a long-term cost reduction strategy applied in timea of crisis, most organizations will decrease their research and development budgets. According to PricewaterhouseCoopers and the National Venture Capital Association, it is evident that sharp decrease in investments of entrepreneurial capital threatens to endanger innovation and long-term growth evidenced in 2009, right after the explosion of the economic crisis in 2008, which can best be seen in the example of the United States, the leading economy of the world, where the last global economic crisis actually started (Figure 1.) [12].

Most organizations are cutting budgets for research and development, unaware that the time of crisis is actually the time for investing in sustainable innovation, since that is the only way to overcome current economic hardships. In the following section of this paper, we will describe how innovation and innovation management can help fight the economic crisis. A special emphasis will be placed on steps in the innovation management process, from the point of their dynamics and results.

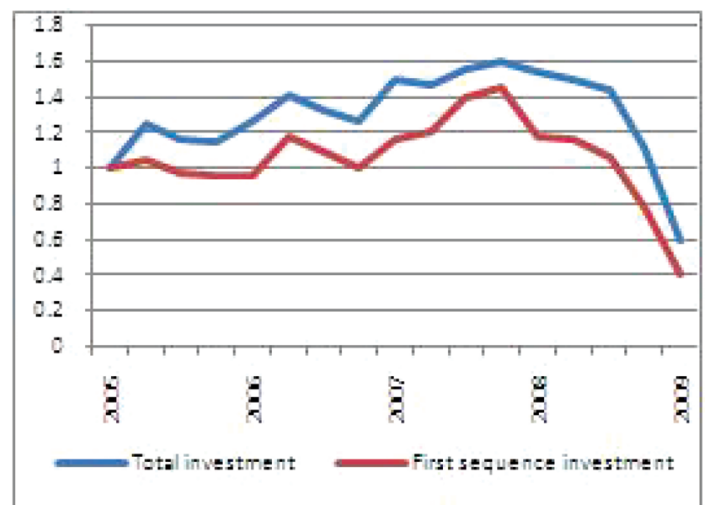

Figure 1. Sharp decrease in investments of entrepreneurial capital in US Source: PricewaterhouseCoopers and The National Venture Capital Association 


\section{Innovations and innovation management as a cure during economic crisis}

An OECD report from June 2009 points to innovation management as the recommended business behavior during the time of economic crisis and to innovations as a key to permanent recovery. Governments can help spin the long-term growth wheel by channeling crisis funds into research and development, entrepreneurial initiatives and education. They should avoid supporting uncompetitive businesses or industries. Finland and Korea are both countries which have increased investments in innovation and education during recent economic crises affecting their territory, and which have benefitted from the exceptionally strong resulting growth [12].

Those two examples of Finland and Korea point to the recommendation that, after the necessary initial savings have been made as the result of the usual managerial behavior during economic crisis, it is desirable for an organization to start investing in innovation. Instead of spending all of organizational energy on cost reduction, which is inevitably the first measure in the struggle against economic downturn, especially in situations where costs before crisis hadn't been managed proactively (Ilić, Milićević, 2009; Milić, 2011, Milićević, llić, 2009), managers should further, as the second step, focus on developing innovative initiatives.

\subsection{Innovation management}

Innovation management is an economic implementation and exploitation of new ideas and discoveries, as well as an implementation of innovative culture in an organization, with the purpose of promoting and developing new ideas and business opportunities (Levi-Jakšić, Marinković, Petković, 2011). Innovation management consists of innovation strategies, innovative culture, ideas management and innovation process implementation (Stošić, 2007). Innovation management targets systematic processes, which organizations use in developing new and improved products, services and business processes. It includes exploitation of creative ideas generated by employees of an organization, as well as establishing a consistent flow of profitable innovation aimed at the market, in a fast and efficient way (Tidd, Bessant, Pavitt, 2001).

Innovation is a process of transferring new ideas to satisfied end-users (Levi-Jakšić, Marinković, Petković, 2011). It represents a conversion of new knowledge into new products and services and has to do with creating values and increasing efficiency, which translates to organizational growth. That is an initial spark, enabling constant progress of an organization and its people. Without innovation, new products, new services and new ways to conduct business would never occur and most organizations would continue to do the same old things in the same old ways forever, and there would be no progress. Therein lays the essence of innovation and its sense. Companies innovate in order to enhance products and services, keep existing and win new consumers, find new ways to solve problems, save money, secure their business, make tasks easier, faster and/or more pleasant, achieve stunning results or have fun.

\subsection{Incremental and radical innovation}

When speaking about innovation management in the time of economic crisis, we should bear in mind that there are two basic types of innovation, based on their respective dynamics. These are incremental and radical innovations [13]. The question is: Which innovation is better in the time of economic crisis?

Typically, managers who choose to invest in innovation in the time of economic downturn will start developing incremental innovation initiatives soon after applying measures for cost reduction. These are easier to implement and they demand capital that is more modest. To be more precise, incremental change exploits the existing technology, comes with a low degree of uncertainty, focuses on costs or enhancement of features of existing products, processes or services and achieves improved competitive edge of an organization in existing markets. It is characterized by linear growth and unpresumptuous market and environment turbulence [13]. As such, it still cannot create and provide great breakthrough and progress of an organization, and does not represent a success guarantee, which are the reasons why it should be used only partially.

However, since the times of crisis, as it has been shown, are the times of radical changes, system and business models changes, as previous crises had shown, it is highly recommended that organizations should attempt to develop no less than radical innovation. 
Radical innovation concerns a complete change of the set business models, or services, or the way of life of consumers and people in general, as well as all stakeholders, through introduction of new products, creation of new business models and offering new benefits, which are to shake the existing forms and principles of doing business. It explores new technologies, focuses on products, processes or services with unprecedented performance features, creates dramatic changes, which transform the existing markets, or industries, or creates new ones. It comes with a high degree of uncertainty and is characterized by rapid growth. As such, it creates dramatic changes, which completely transform the existing markets and industries, or creates new ones and thus gives a chance to organizations, which have embraced it, to take the leading position on the market (Figure 2.) [13].

In the words of Jack Welch, the former legendary President of General Electric, who advised other leaders of this company: «Avoid incremental and look for the quantum leap. Enhance and maintain productivity and quality, but also make a surprise moves - shock your rivals.» [13]. Radical innovation is an innovation that can enable continuous growth and development of an organization within the changing and unstable business environment, such as the one we are facing today. In addition, this constant innovation should be aimed at preservation and improvement of the established values, while giving full attention to consumers and other stakeholders, as well as building a positive, prestigious reputation and image of an organization within its environment.

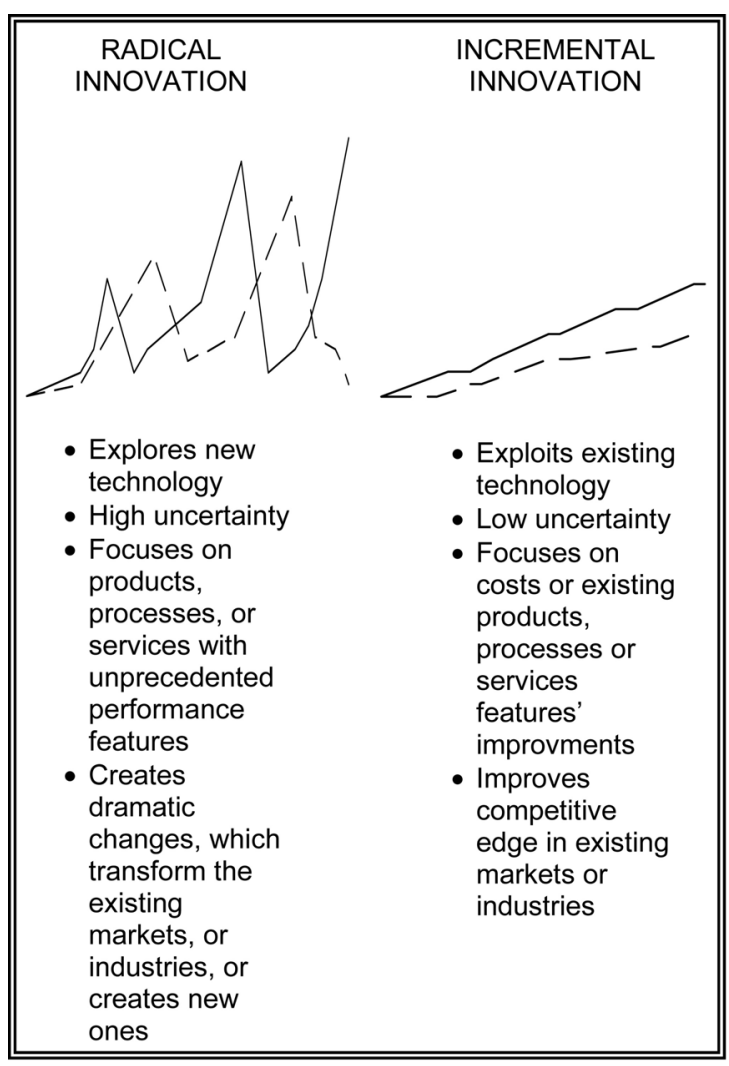

Figure 2. Radical vs. incremental innovation [13]

Comparative characteristics of incremental and radical innovations can be observed in Table 1. [13].

While implementing innovation and its development, innovation portfolio or innovative portfolios offer transparency, which enables organizations to start presenting new products or services. This calls for a balanced presentation of revolutionary products and services with incremental improvements of the existing ones, in order to maintain a constant flow. By clearly following initiatives, companies are able to avoid both market saturation and deficiency in meeting its demands. 


\subsection{Possible areas of innovation}

The seven available areas in which management can turn to innovation during the economic crisis, from the aspect of innovation object, in the field of management are strategy innovation, business innovation, innovation of organization, process innovation, technology innovation, marketing innovation, product/service innovation (Tucker, 2002; Stošić, 2007).

Table 1: Incremental vs. radical innovation [13]

\begin{tabular}{|c|c|c|}
\hline & Incremental innovation & Radical innovation \\
\hline Accent & $\begin{array}{l}\text { Improvements of features of the existing } \\
\text { products, services or processes }\end{array}$ & $\begin{array}{l}\text { Development of new business, products } \\
\text { and/or processes which transform } \\
\text { business economies }\end{array}$ \\
\hline Technology & Exploitation of the existing technology & Research into new technologies \\
\hline Prototype creation & $\begin{array}{l}\text { Correction of shortcomings in the } \\
\text { designing phase }\end{array}$ & $\begin{array}{l}\text { Education of the market about new } \\
\text { technology and learning from the market } \\
\text { with regard to the application value of } \\
\text { that technology }\end{array}$ \\
\hline Trajectory & Linear and continuous & Sporadic and discontinuous \\
\hline Business case & $\begin{array}{l}\text { A detailed plan can be developed at the } \\
\text { beginning of a process }\end{array}$ & $\begin{array}{l}\text { Business model and plan are developed } \\
\text { - created through learning based on } \\
\text { discovery }\end{array}$ \\
\hline $\begin{array}{l}\text { Generating ideas and } \\
\text { recognizing } \\
\text { opportunities }\end{array}$ & $\begin{array}{l}\text { It happens at the beginning - critical } \\
\text { events are predicted and anticipated at } \\
\text { full speed }\end{array}$ & $\begin{array}{l}\text { It happens sporadically through the life } \\
\text { cycles, often as a reaction to } \\
\text { discontinuation in the project trajectory }\end{array}$ \\
\hline Key players & Formal cross functional teams & $\begin{array}{l}\text { Cross-functional individuals, informal } \\
\text { networks }\end{array}$ \\
\hline Process & Formal, phase model & $\begin{array}{l}\text { Informal, flexible model in early phases } \\
\text { due to uncertainty } \rightarrow \text { formal in later } \\
\text { phases after uncertainty had been } \\
\text { reduced }\end{array}$ \\
\hline $\begin{array}{l}\text { Organizational } \\
\text { structures }\end{array}$ & $\begin{array}{l}\text { Cross functional project team works } \\
\text { within a business unit }\end{array}$ & $\begin{array}{l}\text { Project starts in IR } \rightarrow \text { migrates into } \\
\text { organization of the incubation period } \rightarrow \\
\text { transition into the goal-guided project } \\
\text { organization }\end{array}$ \\
\hline $\begin{array}{l}\text { Resources and } \\
\text { competencies }\end{array}$ & $\begin{array}{l}\text { Standard allocation of resources - team } \\
\text { has all the required competencies for } \\
\text { carrying out a process }\end{array}$ & $\begin{array}{l}\text { Creative acquisition of competencies } \\
\text { and resources from various internal and } \\
\text { external sources }\end{array}$ \\
\hline $\begin{array}{l}\text { Ways of inclusion of } \\
\text { operating department }\end{array}$ & Formal inclusion from the beginning & $\begin{array}{l}\text { Informal in early phases } \rightarrow \text { formal in later } \\
\text { phases }\end{array}$ \\
\hline
\end{tabular}

1. Strategy innovation - Relates to challenging of the existing industrial methods of creating values for consumers in order to satisfy the newly found consumer needs, augment added value and create new markets and new consumer groups for the sponsor company. Strategy innovation refers to:

- development of innovative organizational strategy,

- development of innovative strategies for corporate growth,

- development of enterprise strategies,

- development of innovative competitive strategies.

2. Business innovation - Business Innovation refers to the generation of new business principles, concepts, and practices in the field of business as a whole, or its individual parts. Specifically, business innovation can be achieved in the form of:

- new business models,

- new management models,

- new approach to value chain management,

- new approach to information, ideas, knowledge management,

- new forms of strategic partnership,

- new forms of sales and consumer service. 
3. Innovation of organization - Organizational innovation is the introduction of new methods of organizing management procedures, new ways of sharing responsibilities and decision-making between employees and new structuring of business activities through organizational structure changes, as well as new ways of organizing company relations with other companies or institutions. Innovation of organization encompasses:

- partnership with new people,

- better internal climate, motivation and communication,

- new forms of employees' and stakeholders' participation,

- better innovation culture and innovation system,

- new systems for knowledge, ideas and creativity management,

- more efficient innovation measures.

4. Product/service innovation - Product/service innovation is the result of introducing a new way to solve consumer problems - through the development of new product or service, or through significantly improving the existing ones in terms of performance - which bring benefit to both consumer and the sponsor company. Product/service innovation encompasses:

- presentation of new products/services to the public,

- presentation of new products/services to the company and new markets,

- product and/or service lines expansion,

- enhancement of products and services.

It includes significant improvements in technical specifications, components and materials, the implemented software, facilitating the use of the product, or functional characteristics of the product.

5. Process innovation - Process innovation increases profitability, decreases costs, improves efficiency, raises productivity and increases the level of job satisfaction. They also bring better products or services to consumers. Process innovation involves the adoption of new or significantly improved methods of production and business process itself or some of its parts. Process innovation implies:

- innovative system of business process management,

- new production processes and techniques,

- improvements of quality and efficiency of production and business process,

- linear and cleaner production methods.

6. Technology innovation - Technology innovations are related to new products and processes and significant technological changes in products and processes. As such, they contain:

- technologic strategy and a road map,

- development of new strategies,

- new ways of technology commercialization and exploitation,

- technology acquisition.

7. Marketing innovation - Marketing innovation is the implementation of a new marketing method involving significant changes in the field of marketing mix. Marketing innovation refers to:

- innovative design and presentation techniques,

- new forms of differentiation, positioning and advertising,

- innovative methods of distribution and consumer service,

- Innovative methods and strategies of forming sales price.

In all these areas of innovation, according to the current definition in the EU, one should distinguish seasonal and other regular and routine changes, minor improvements, or modifications from innovation (Stošić, 2007). Innovation involves such changes in these areas of innovation, which are not previously applied in the company and which are the result of strategic management decisions.

Of the specified possible innovation areas, two of the most represented ones are product and process innovation. As a third type, there occurs hybrid innovation, which combines process and product innovation. Product innovation refers to the development of new or significantly improved products or services and their placement in the market. Process innovation deals with improvement of business functions necessary for profit realization from products and service insurance. It comprises, but it is not limited to, strategic planning, supplies control, logistics, employee training, communications, financing and marketing. The greatest focus 
and attention in the area of innovation is directed precisely at the product innovation - especially the radical product innovation. The reason is simple; it has the greatest profit potential, but it also carries the greatest risk. However, despite this fact, incremental innovation is the most frequent form of the innovation initiatives in many organizations, comprising on average around $80 \%$ of all innovation investments of an organization (Stošić, 2007).

Conclusions and recommendations

In the first half of the second decade of the XXI century, recession and financial crisis will continue to play the main part in innovation planning. Most companies will decrease their research and development budgets, unaware that a time of economic downturn is precisely the time to invest in sustainable innovation, because that is the only way to exit the actual crisis. With this in mind and considering that the time of economic crisis is the time of radical changes, system changes, business models, as the previous crises have proven, it would be very desirable for organizations to try to develop radical innovation.

It is highly recommended that, after the initial costs reduction and in accordance with organizational potential, the organization should approach radical innovation development, followed by diffusion of incremental innovation. Given that incremental innovation cannot provide strong market breakthrough of the organization and its future growth and development, the accent should be precisely on radical innovation development, that is, innovation that will enable strong vicissitude as the basis for establishing a powerful leadership position in the market and achievement of continuous profit flow.

Innovative strategies are crucial for sustaining and improving current market position of the organization, both in prospective economic times and during the times of economic downturn. It has been established that a lack of innovation and innovative strategies under the normal conditions for conducting business can result in failure and yielding the leading position to others, or in deterioration of the current market position (Levi-Jakšić, Marinković, Petković, 2011). However, the same holds true during the times of economic crisis.

Even in the time of crisis, according to the OECD report dated June 2009, competitiveness of an organization equals to the need to establish innovative strategies, as a dynamic response to hardships and the only vital direction of organizational survival and development. Innovative strategies are achieved by starting from the external "forces" of competitiveness, that is, the influence of the surroundings and the market above all else, but also starting from the internal "forces" of competitiveness, i.e., resources and abilities ingrained in competencies which represent the internal forces of an organization, through which it reinforces its competitive power (Trott, 2005). The possible areas of innovation are strategy innovation, business innovation, innovation of organization, product innovation, process innovation, technology innovation and marketing innovation, where product innovation and process innovation, as well as their combination, have the greatest importance, as was singled out by J. Schumpeter as one of the most significant factors for economic and technological development of a society. J. Schumpeter marked innovation as the basic factor of economic development. He was one of the first scientists who recognized the importance of new product development - product innovation for economic development, considering competitiveness achieved through introduction of a new product by far more important than the one based on marginal changes of the existing products' prices (Stošić, 2007).

Also, the importance of innovation for an organization and global economy was emphasized by C. Freeman, who formulated the thesis that not to innovate means to disappear (Levi-Jakšić, Marinković, Petković, 2011; Stošić, 2007; Trott, 2005).

It can be concluded that innovation and innovation management represent an irreplaceable instrument in the time of economic crisis, the one that will to a great degree help overcome downturn and even improve business processes in use thus far - along with models, products and services, technologies and marketing - as well as the actual market position of organizations, and the quality of life itself. 


\section{REFERENCES}

[1] Cost Reduction and Control Best Practices: The Best Ways for a Financial Manager to Save Money, IOMA, 2006

[2] Hart R., Cutting Costs Effectively in Recession and Recovery: Finding Hidden Potential, Making TradeOffs and Managing the Process, Recession Storming Media, 2009

[3] Ilić B., Milićević V., Menadžment troškova - strategijski okvir, FON, Beograd, 2009.

[4] Levi-Jakšić M., Marinković S., Petković J., Menadžment inovacija i tehnološkog znanja, FON, Beograd, 2011.

[5] Milić T., Strategije redukcije troškova u doba krize, Management, br. 61, Godina XVI, p. 65-71, FON, Beograd, Decembar 2011.

[6] Milićević V., Ilić B., Effective Cost Management and Customer Profitability Measurement, Management, br. 53, Godina XIV, p. 5-12, FON, Beograd, Decembar 2009.

[7] Stošić B., Menadžment inovacija, FON, Beograd, 2007.

[8] Sundbo J., The Strategic Management of Innovation, Edward Elgar, 2001

[9] Tidd J., Bessant J., Pavitt K., Managing Innovation, John Wiley \& Sons, Chichester, 2001

[10] Trott P., Innovation Management and New Product Development, Prentice Hall, London, 2005

[11] Tucker B. R., Driving Growth Through Innovation, Berrett-Koehler Publishers Inc., San Francisco, CA, 2002

[12] http://www.oecd.org/document/22/0,3746,en_2649_37417_42913302_1_1_1_37417,00.html, mart 2012. www.hbs.com, Radical Innovation, Harvard Business School, 2000

Receieved: June 2012. Accepted: March 2013.

\section{University of Belgrade, Faculty of Organizational Sciences}

Tanja Milić is a teaching assistant within the Department of Management at the Faculty of Organizational Sciences, University of Belgrade. Her research field is Business Economics and Macroeconomics. 